\title{
Pengaruh Ewom Terhadap Brand Image Dan Purchase Intention Produk Innisfree Di Jakarta
}

\author{
Theresia Yonita dan Herlina Budiono \\ Program Studi S1 Manajemen Fakultas Ekonomi, Universitas Tarumanagara, Jakarta \\ Email: theresia.115150261@stu.untar.ac.id
}

\begin{abstract}
The purpose of this study is to find out 1) whether there is an effect of EWOM on Purchase Intention 2) whether there is an influence of the EWOM on Brand Image 3) whether there is an Influence of Brand Image on Purchase Intention 4) whether Brand Image can meditiate EWOM influence on Purchase Intention. The population in this study were Innisfree products users in Jakarta. The sample used in this study was 100 respondents from Innisfree products users in Jakarta. The sampling technique used was probability sample with simple random sampling method. Overall the results of this study are 1) EWOM has a significant and positive effect on Purchase Intention, 2) EWOM has a significant and positive effect on Brand Image, 3) Brand Image has a significant and positive effect on Purchase Intention 4) Brand Image has significantly and positively meditiate the effect of EWOM on Purchase Intention.
\end{abstract}

Keywords: EWOM, Brand Image, Purchase Intention

\begin{abstract}
Abstrak: Tujuan penelitian ini adalah untuk mengetahui 1) apakah terdapat pengaruh EWOM terhadap Niat pembelian 2) apakah terdapat pengaruh EWOM terhadap Citra Merek 3) apakah terdapat pengaruh Citra Merek terhadap Niat pembelian 4) apakah terdapat pengaruh EWOM terhadap Niat Pembelian melalui mediasi Citra Merek. Populasi dalam penelitian ini adalah pengguna Produk Innisfree di Jakarta. Sampel yang digunakan pada penelitian ini yaitu 100 responden pengguna produk Innisfree di Jakarta. Teknik pengambilan sampel yang digunakan yaitu probability sampling dengan metode pengambilan sampel simple random sampling. Secara keseluruhan hasil dari penelitian ini yaitu 1) EWOM berpengaruh signifikan dan positif terhadap Niat Pembelian 2) EWOM berpengaruh signifikan dan positif terhadap Citra Merek, 3) Citra Merek berpengaruh signifikan dan positif terhadap Niat Pembelian 4) Citra Merek secara signifikan dan positif memediasi pengaruh EWOM terhadap Niat Pembelian.
\end{abstract}

Kata kunci: EWOM, Citra Merek, Niat Pembelian.

\section{LATAR BELAKANG}

Sangat umum bagi orang untuk menilai kesan pertama dari penampilan luar, oleh karena itu penampilan yang menarik menjadi sangat penting bagi wanita. Wan et al. (2001) mengungkapkan bahwa orang rela mengeluarkan uang untuk produk yang berhubungan dengan penampilan, yang akan meningkatkan konsep diri mereka dan membuat mereka merasa, terlihat, dan berbau harum.

Hal ini terlihat bahwa dalam 20 tahun terakhir, pasar kecantikan global telah tumbuh ratarata sebesar 4,5\% per tahun (CAGR), dengan tingkat pertumbuhan per tahun sekitar 3\% sampai 5,5\%. Juga dikenal dengan sebutan kosmetik dan produk perawatan diri, pasar ini telah membuktikan kemampuannya untuk mencapai pertumbuhan yang stable dan terus 
menerus serta kapasitasnya untuk bertahan dalam kondisi ekonomi yang tidak menguntungkan (Łopaciuk, A., \& Łoboda, M., 2013).

Analis di Goldman Sachs memperkirakan bahwa industri kecantikan global terdiri dari perawatan kulit senilai \$24 miliar; cosmetics $\$ 18$ miliar; $\$ 38$ miliar produk perawatan rambut; dan $\$ 15$ miliar parfum dan mengalami pertumbuhan hingga $7 \%$ per tahun, lebih dari dua kali lipat tingkat PDB negara maju. Pemimpin pasar sektor ini, L'Oreal, telah memiliki pertumbuhan laba tahunan gabungan sebesar 14\% selama 13 tahun. Penjualan Beiersdorf's Nivea mengalami pertumbuhan $14 \%$ per tahun dibandingkan periode yang sama. (The Economist, 22 Mei 2003).

Demikian juga halnya dengan Korea Selatan, pasar kosmetik korea merupakan pasar terbesar ke-12 di seluruh dunia, bernilai \$ 5,2 miliar pada tahun 2009 dan merupakan penyumbang terbesar ekspor di Korea dengan pertumbuhan yang pesat hingga mencapai 4,979,084 unit pada tahun 2017 (Korea Pharmaceutical Traders Association, 2018). Hingga saat ini produk kosmetik Korea telah di ekspor ke 119 negara di seluruh dunia (Korea Pharmaceutical Traders Association, 2018) dan secara spesifik sangat mudah ditemui, tidak hanya di toko retail di pasar malam dan konter-konter di department store, tetapi juga melalui internet online shopping dan TV shopping. (Łopaciuk \& Łoboda, 2013).

Innisfree merupakan salah satu merek yang diluncurkan perusahaan kosmetik dan skincare terbesar di Korea, Amore Pacific pada 2002, sebagai merek eco-friendly yang pertama. Pada tahun 2005, perusahaan membuka toko merek pertama mereka dan menempati posisi pertama pada Consumer Well-being Index. Pada 2007 membuka toko ke100 mereka dan mencapai penjualan 100 milyar Won pada 2009.

Pada tahun 2011, merek ini melaporkan penjualan lebih dari 140,5 miliar Won $(\$ 123,1$ juta) dari lebih dari 434 lokasi di Korea Selatan. Amore Pacific membuka toko flagship pertama merek di Shanghai pada 25 April 2012. Perusahaan terus berkembang dan pada tahun 2013, membuka toko di Hong Kong, Singapura dan India. Innisfree terus melebarkan sayapnya hingga pada 2017, perusahaan telah memiliki flagship di Malaysia, Shanghai, Vietnam, Chengdu, dan Indonesia.

Karena perkembangan yang semakin beragam dalam industri produk perawatan kecantikan, bisnis menggunakan situs web mereka untuk terhubung dengan komunitas online, memungkinkan konsumen untuk memposting pengalaman dan komentar penggunaan produk mereka untuk menghemat waktu dan biaya pencarian bagi pengguna (P. Chatterjee, 2001). Dengan menggunakan layanan situs web berbasis komunitas, konsumen dapat meningkatkan pemahaman mereka atas produk dan layanan yang diberikan dan pada gilirannya melakukan keputusan pembelian (J.G. Udo dkk., 2010).

\section{KAJIAN TEORI}

Pada penelitian ini, menurut Erkan (2016) terkait dengan dua teori yaitu Information Adoption Model (IAM) dan komponen-komponen yang terkait Theory of Reasoned Action (TRA).

Information Adoption Model (IAM) merupakan teori yang dikemukakan pertama kali oleh Sussman et al. (2003), yang menjelaskan bagaimana individual mengadopsi informasi dan kemudian mengubah niat dan perilaku mereka dalam platform komunikasi dengan mediasi komputer. 
IAM didasarkan pada Technology Accepted Model (TAM) dan model proses ganda pengaruh informasi (ELM), meskipun teori TAM diterima secara luas, fokus utama TAM adalah kepada sistem informasi dan penggunaan individual komputer, tetapi mengabaikan proses sosial (Riffai et al., 2012), sementara ELM menjelaskan bagaimana penerima dipengaruhi oleh informasi dalam pesan dan bagaimana kemudian pesan tersebut dapat mendeskripsikan perubahan bentuk perilaku dan menjelaskan proses dibalik efektifitas komunikasi persuasif (Petty \& Cacioppo, 1986).

IAM memiliki 4 (empat) komponen integrasi yang menjelaskan bagaimana orang dapat terpengaruh informasi platform komunikasi dimediasi perangkat komputer, yaitu: kualitas argumen, kredibilitas sumber, kegunaan informasi dan adopsi informasi (Erkan \& Evans, 2016).

Model ini menjelaskan informasi pada platform komunikasi dengan mediasi perangkat komputer, karena itu IAM sangat cocok bagi penerapan EWOM (Cheung et al., 2008; Cheung, Luo, Sia, \& Chen, 2009; Shu \& Scott, 2014).

Theory of Reasoned Action (TRA) merupakan teori yang dikembangkan Ajzen dan Fishbein (1980). Berdasarkan TRA, perilaku dipengaruhi oleh niat untuk membentuk perilaku dan niat merupakan fungsi dari sikap perilaku dan norma subjektif. Penelitian ini hanya menggunakan 2 (dua) komponen TRA yaitu sikap dan niat perilaku.

Perilaku pembelian terbuka, sehingga dapat dipengaruhi faktor-faktor eksternal seperti perubahan pendapatan dan promosi yang tidak terduga (De Cannicre, De Pelsmacker, \& Geuens, 2009; Foxall, 2005; Infosino, 1986; Morrison, 1979; Sun \& Morwitz, 2010), oleh karena itu kebutuhan akan informasi ditemukan sebagai sikap konsumen terhadap informasi EWOM (Chu \& Kim, 2011; Hennig-Thurau, Gwinner, Walsh, \& Gremler, 2004; Wolny \& Mueller, 2013).

Erkan dan Evans (2016) mempelajari pengaruh EWOM pada niat pembelian konsumen di sosial media dengan mengintegrasi IAM dan komponen-komponen terkait TRA, dengan menyebarkan kuisioner kepada 384 pelajar di universitas di UK. Hasil penelitian tersebut menunjukkan adanya pengaruh antara pengadopsian informasi pada purchase intention dan kegunaan informasi pada kredibilitas informasi, sementara kualitas, kredibilitas dan kebutuhan akan informasi ditemukan mempengaruhi kegunaan informasi. Dari teori-teori di atas dapat disimpulkan bahwa IAM menjelaskan karakteristik informasi EWOM sementara komponen-komponen yang terkait dengan TRA menjelaskan perilaku konsumen terhadap informasi EWOM.

Kerangka Pemikiran dalam penelitian ini seperti yang digambarkan dibawah ini: 


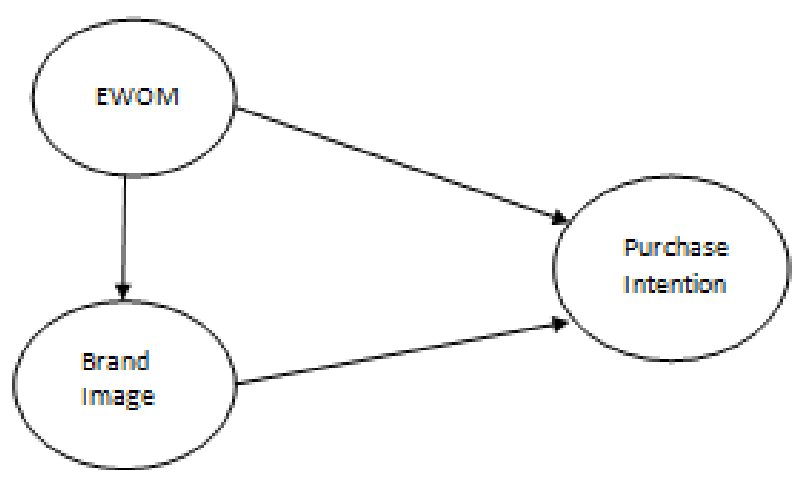

Gambar 1. Kerangka Pemikiran

Hipotesis dari model yang dibangun di atas adalah sebagai berikut:

H1: EWOM memiliki pengaruh positif terhadap purchase intention pelanggan Innisfree di Jakarta.

$\mathrm{H}$ 2: EWOM memiliki pengaruh positif terhadap brand image pelanggan Innisfree di Jakarta.

H3: Brand image memiliki pengaruh positif terhadap purchase Intention pelanggan Innisfree di Jakarta.

H4: EWOM memiliki pengaruh positif terhadap purchase intention pelanggan Innisfree di Jakarta melalui mediasi brand image.

\section{METEDOLOGI}

Desain penelitian pada hakikatnya merupakan suatu strategi untuk mencapai tujuan penelitian yang telah ditetapkan dan berperan sebagai pedoman atau penuntun peneliti pada seluruh proses penelitian (Alsa, 2003).

Desain penelitian yang digunakan dalam penelitian ini adalah penelitian deskriptif. Menurut Sugiyono (2013:147), metode deskriptif adalah metode yang digunakan untuk menganalisis data dengan cara mendeskripsikan atau menggambarkan data yang telah terkumpul sebagaimana adanya tanpa bermaksud membuat kesimpulan yang berlaku untuk umum atau generalisasi lebih rinci atau membedakannya dengan fenomena lain. Aritonang (1998:91) menambahkan bahwa dalam penelitian deskriptif tidak ada variabel yang dimanipulasi, data yang pada penelitian deskriptif merupakan 'given' bukan data yang diciptakan dan juga subyek atau responden pada penelitian ini cenderung lebih banyak daripada penelitian eksploratif.

Penelitian ini menggunakan metode kuantitatif. Menurut Sugiyono (2012), metode penelitian kuantitatif dapat diartikan sebagai metode penelitian yang berlandaskan pada filsafat positivisme digunakan untuk meneliti pada populasi atau sampel tertentu.

Populasi dalam penelitian ini adalah seluruh pengguna produk Innisfree di Jakarta, dengan pengambilan sampel dan bukan populasi, dengan mempertimbangkan ukuran populasi jumlah pengguna produk Innisfree di Jakarta yang besar. diperoleh dengan pembagian kuisioner yang dibuat dengan menggunakan google form dan kemudian disebarluaskan 
kepada responden melalui berbagai platform media sosial seperti line, instagram, dan whatsapp.

Adapun teknik pengambilan sampel yang digunakan dalam penelitian ini adalah probability sampling yaitu simple random sampling sehingga setiap anggota populasi atau semesta tadi memiliki peluang yang sama untuk terpilih atau terambil.

Jenis data yang dapat digunakan dalam penelitian ini adalah data primer. Data primer adalah seluruh data yang telah dikumpulkan sendiri oleh peneliti agar dapat menjawab suatu permasalahan penelitiannya.

Skala Likert dinyatakan sebagai skala ordinal karena Gadermann et al. (2012) merekomendasikan untuk menggunakan versi ordinal, ketika data yang dimiliki merupakan tipe likert dengan dua sampai tujuh pilihan respons, alternatif tanggapannya bersifat kategorik yang dinyatakan dalam lima kategori, yaitu(1) sangat tidak setuju, (2) tidak setuju, (3) netral, (4) setuju dan (5) sangat setuju. Dinyatakan sebagai skala ordinal karena kata 'sangat' pada alternatif tanggapan tersebut menunjukkan pemeringkatan, jenjang. maka, perlakuan skor yang dapat diperoleh melalui skala Likert sebagai skala nominal atau ordinal tidak menjadi masalah (Aritonang R., 2007: 183).

\section{Hasil Uji Statistik}

Pengujian validitas data dalam penelitian ini diukur dengan menggunakan nilai convergent validity, dan discriminant validity. Nilai convergent validity diuraikan dengan menggunakan Average Variance Extracted (AVE) dan loading factor, loading factor harus dapat lebih besar dari 0,6 dan jika nilai loading faktor dibawah dari 0,4 maka indikator tersebut dapat dihapuskan dan nilai Average Variance Extracted (AVE) harus dapat lebih besar dari 0,5. Nilai AVE pada penelitian ini menunjukkan EWOM sebesar 0,657, brand image 0,608 , dan purchase intention sebesar 0,725 serta nilai loading factor yang dimiliki masing-masing variabel pada penelitian ini memenuhi kriteria validitas konvergen yaitu dengan nilai loading factor lebih besar dari 0,7.

Pengujian Reliabilitas data dalam Penelitian ini menggunakan cronbach's alpha dan composite reliability untuk dapat menguji reliabilitas. Suatu data dapat dinyatakan reliabel jika hasil dari nilai cronbach's alpha $>0,6$. Berikut ini merupakan hasil dari nilai cronbach's alpha dan composite reliability. Cronbach's alpha EWOM mempunyai nilai 0,739 , brand image mempunyai nilai 0,785 , dan purchase intention mempunyai nilai sebesar 0,811 .

Pengujian koefisien determinasi dilakukan untuk mengetahui persentase pengaruh variabel independen yaitu EWOM dengan dimediasi brand image untuk memprediksi variabel dependen purchase intention. Hasil pengujian pada coefficient of determination $\left(\mathrm{R}^{2}\right)$ adalah sebesar $36 \%$ variabel EWOM dapat menjelaskan variabel brand image dan sisanya dijelaskan variabel lain diluar model, sementara sebesar 50,3\% variabel purchase intention dapat dijelaskan oleh variabel EWOM dan brand image dan sisanya dijelaskan variabel lainnya diluar model.

Pengujian cross-validated redudancy digunakan untuk mengetahui konstruk variabelvariabel yang ada dalam penelitian ini dalam mengukur model penelitian yang telah terbentuk sebelumnya. hasil pengujian $\mathrm{Q}^{2}$ untuk variabel brand image sebesar $0,224\left(\mathrm{Q}^{2}>\right.$ $0,15)$ yang berarti konstruk variabel bersifat sedang dalam mengukur model penelitian yang ditetapkan dan untuk variabel purchase intention $0,328\left(\mathrm{Q}^{2}>0,15\right)$ yang juga berarti konstruk variabel bersifat sedang dalam mengukur model penelitian yang ditetapkan. 
Kriteria dalam pengujian cross-validated Redudancy adalah $\mathrm{Q}^{2}>0$, berarti konstruk variabel dalam penelitian ini relevan dalam mengukur model penelitian sebelumnya.

Pengujian GoF dilakukan untuk menguji kecocokan model pada penelitian ini, dengan melihat nilai NFI. Nilai NFI berkisar antara 0 sampai dengan 1, semakin mendekati 1 maka model tersebut dinyatakan semakin fit. Dari hasil yang diperoleh pada pengujian tabel di atas hasil pengujian model sebesar 0,724 dimana mendekati 1 maka dapat disimpulkan bahwa penelitian ini dianggap baik.

Pengujian Hipotesis dalam penelitian ini menggunakan pengujian dengan $t$-statistic, $\mathrm{p}$ values, dan yang original sample untuk dapat menentukan apakah hipotesis-hipotesis yang telah dibuat dalam penelitian ini mempunyai pengaruh yang siginifikan dan positif. Hubungan dinyatakan signifikan apabila nilai $t$-statistic $>1,96$ dan $\mathrm{p}$-values dibawah 0,05 $(5 \%)$.

Hasil pengujian pada tabel di atas menunjukkan nilai $t$ statistics EWOM terhadap purchase intention adalah sebesar 3,036 ( $t$-statistic $>1,96)$ dan $p$ values sebesar $0,002(p$ values < 0,05) yang berarti signifikan. Nilai original sample adalah sebesar 0,235 yang menunjukkan bahwa arah pengaruh adalah positif. Sehingga dapat disimpulkan bahwa EWOM memiliki pengaruh positif terhadap purchase intention.

Hasil pengujian pada tabel di atas menunjukkan nilai $t$ statistics EWOM terhadap brand image adalah sebesar 11,861 ( $t$-statistic $>1,96)$ dan $p$ values sebesar 0,00 ( $p$ values $<0,05)$ yang berarti signifikan. Nilai original sample adalah sebesar 0,600 yang menunjukkan bahwa arah pengaruh adalah positif. Sehingga dapat disimpulkan bahwa EWOM memiliki pengaruh positif terhadap brand image.

Hasil pengujian pada tabel di atas menunjukkan nilai $t$ statistics brand image terhadap purchase intention adalah sebesar 6,485 (t-statistic $>1,96)$ dan $p$ values sebesar 0,00 ( $p$ values $<0,05$ ) yang berarti signifikan. Nilai original sample adalah sebesar 0,542 yang menunjukkan bahwa arah pengaruh adalah positif. Sehingga dapat disimpulkan bahwa brand image memiliki pengaruh positif terhadap purchase intention.

Pengujian efek pemediasi dilakukan karena efek variabel independen terhadap variabel dependen adalah signifikan dan dapat dilihat melalui nilai indirect effect. nilai direct effect variabel EWOM terhadap purchase intention adalah sebesar 0,235 sedangkan pada nilai indirect effect variabel EWOM terhadap purchase intention melalui brand image adalah sebesar 0,325 . Hal ini menunjukkan terjadinya peningkatan nilai indirect effect setelah ditambahkannya variabel mediasi dibandingkan sebelum ditambahkan variabel mediasi.

Nilai original sample sebesar 0,325 menunjukkan bahwa arah hubungan positif dengan nilai t statistics sebesar 5,152 ( $\mathrm{t}$-statistic $>1,96$ ) dan $\mathrm{p}$ values sebesar 0,00 ( $\mathrm{p}$ values $<0,05)$ yang berarti signifikan. Dapat disimpulkan bahwa EWOM memiliki pengaruh positif terhadap purchase intention pelanggan Innisfree di Jakarta melalui mediasi brand image.

Penjelasan uji hipotesis di atas adalah EWOM memiliki pengaruh positif terhadap purchase intention, EWOM memiliki pengaruh positif terhadap brand image. brand image memiliki pengaruh positif terhadap purchase intention, dan EWOM memiliki pengaruh positif terhadap purchase intention pelanggan Innisfree di Jakarta melalui mediasi brand image. 


\section{DISKUSI}

EWOM terbukti dapat berpengaruh secara signifikan terhadap purchase intention karena hasil nilai $t$ statistics EWOM terhadap purchase intention adalah sebesar 3,036 yang berarti lebih besar dari 1,96 dan $p$ values sebesar 0,002 yang berarti lebih kecil dari 0,05 . Sehingga dapat disimpulkan bahwa EWOM memiliki pengaruh yang signifikan terhadap purchase intention pada pengguna produk Innisfree di Jakarta. Hasil dari penelitian ini juga menunjukkan bahwa EWOM memiliki pengaruh yang positif terhadap purchase intention karena mempunyai original sample sebesar 0,235 yang berarti terdapat pengaruh positif EWOM terhadap purchase intention. Berdasarkan dari hasil penelitian ini dapat disimpulkan bahwa EWOM memiliki pengaruh yang signifikan dan positif terhadap purchase intention.

EWOM juga mempunyai $t$ statistics terhadap brand image sebesar 11,861 yang berarti lebih besar dari 1,96 dan dan $p$ values sebesar 0,00 yang berarti lebih kecil dari 0,05. Sehingga dapat disimpulkan bahwa EWOM memiliki pengaruh yang signifikan terhadap brand image pada pengguna produk Innisfree di Jakarta. Hasil dari penelitian ini juga menunjukan bahwa EWOM mempunyai pengaruh yang positif terhadap brand image karena memiliki original sample sebesar 0,600 yang berarti terdapat pengaruh positif EWOM terhadap brand image. Berdasarkan dari hasil penelitian ini dapat disimpulkan bahwa EWOM mempunyai pengaruh yang signifikan dan positif terhadap brand image.

Brand image terbukti dapat berpengaruh secara signifikan terhadap purchase intention karena hasil nilai $t$ statistics brand image terhadap purchase intention adalah sebesar 6,485 yang berarti lebih besar dari 1,96 dan $p$ values sebesar 0,00 yang berarti lebih kecil dari 0,05. Sehingga dapat disimpulkan bahwa brand image memiliki pengaruh yang signifikan terhadap purchase intention pada pengguna produk Innisfree di Jakarta. Hasil dari penelitian ini juga menunjukkan bahwa brand image memiliki pengaruh yang positif terhadap purchase intention karena mempunyai original sample sebesar 0,542 yang berarti terdapat pengaruh positif EWOM terhadap purchase intention. Berdasarkan dari hasil penelitian ini dapat disimpulkan bahwa EWOM memiliki pengaruh yang signifikan dan positif terhadap purchase intention.

Berdasarkan pengujian pemediasi yang dilakukan nilai original sample sebesar 0,325 menunjukkan bahwa arah hubungan positif dengan nilai $t$ statistics sebesar 5,152 yang berarti lebih besar dari 1,96 dan $\mathrm{p}$ values sebesar 0,00 yang berarti lebih kecil dari 0,05 yang berarti signifikan. Dapat disimpulkan bahwa EWOM memiliki pengaruh positif terhadap purchase intention pelanggan Innisfree di Jakarta melalui mediasi brand image.

\section{PENUTUP}

$\left.{ }^{1}\right)$ Berdasarkan hasil pengujian data dalam penelitian ini, terdapat pengaruh EWOM terhadap purchase intention pengguna produk Innisfree di Jakarta, terdapat pengaruh EWOM terhadap brand image produk Innisfree di Jakarta, terdapat pengaruh brand image terhadap purchase intention pengguna produk Innisfree di Jakarta dan terdapat pengaruh EWOM terhadap purchase intention pengguna produk Innisfree di Jakarta melalui mediasi brand image.

$\left.{ }^{2}\right)$ Keterbatasan dari penelitian ini dikarenakan: (1) Subjek dalam penelitian ini dibatasi hanya pelanggan produk Innisfree di wilayah Jakarta. Dengan hanya memiliki 4 variabel 
tersebut dirasa masih sangat kurang karena variabel lain yang dapat mempengaruhi Intensi Kewirausahaan masih banyak antara lain Pendidikan kewirausahaan, locus of control, dan sikap. (2) Jumlah subjek penelitian yang terbatas yaitu hanya 100 sampel, sehingga tidak dapat digeneralisasikan. Yang seharusnya dapat lebih dari 100 orang responden karena melihat ada banyaknya pengguna produk Innisfree. Hal ini disebabkan karena keterbatasan waktu dalam penelitian ini. (3) Variabel-variabel yang digunakan untuk memprediksi purchase intention hanya EWOM dan brand image. . Dengan hanya memiliki 3 variabel tersebut dirasa masih sangat kurang karena variabel lain yang dapat mempengaruhi purchase intention.

${ }^{3}$ )Berdasarkan dengan hasil penelitian yang telah dilakukan, maka peneliti dapat memberikan beberapa saran yang diharapkan dapat memberi manfaat. Berikut ini merupakan saran-saran dari peneliti: (1) Innisfree harus meningkatkan electronic word of mouth untuk meningkatkan niat pembelian pelanggan, hal tersebut dapat dilakukan dengan cara mengamati EWOM yang berkembang seputar produk atau membuat forum diskusi pada website resmi Innisfree untuk tempat konsumen membagikan pengalaman (2) b.

Terbukti terdapat pengaruh positif brand image terhadap purchase Intention pelanggan Innisfree di Jakarta, Sehingga Innisfree harus mempertahankan bahkan meningkatkan brand image yang dimiliki perusahaan dengan cara mempertahankan kualitas baik yang dimiliki produk Innisfree dan juga meluncurkan produk-produk baru yang unik dan memiliki kualitas yang lebih baik dibandingkan produk-produk milik pesaing. (3) Dapat meningkatkan niat pembelian produk Innisfree dengan menggabungkan brand image dengan EWOM yang dimiliki Innisfree dengan cara meningkatkan kualitas produk yang dimilikinya dengan membangun asosiasi merek yang kuat, favorable, dan unik di mata para konsumen untuk memperbesar pengaruh merek terhadap niat pembelian. Dalam peluncuran produk baru Innisfree dapat bekerja sama dengan makeup artis terkenal untuk melakukan demo makeup atau beauty class atau dapat bekerjasama dengan influencer ternama untuk memberikan ulasan seputar produk sehingga dapat meningkatkan penyebaran EWOM yang positif dan meningkatkan purchase intention konsumen. (4) d.

Bagi penelitian selanjutnya dapat dilakukan penelitian seputar motivasi penggunaan sosial media untuk melakukan EWOM, selain itu dapat menambahkan variabel-variabel bebas yang belum diteliti dalam penelitian ini seperti celebrity endorsement, brand loyalty, brand awareness, dan brand association serta dapat memperluas cakupan pengambilan sampel dan juga jumlah pengambilan sampel yang diambil guna mendapatkan data yang lebih akurat dan dapat di generalisasikan.

\section{DAFTAR PUSTAKA}

Alsa, A. (2003). Pendekatan Kuantitatif dan Kualitatif Serta Kombinasinya dalam Penelitian Psikologi. Yogyakarta: Pustaka Pelajar.

Aritonang, R., \& Lerbin, R. (1998). Penelitian pemasaran. UPT Penerbitan Universitas Tarumanagara. Jakarta.

Indonesia.

(2007). Riset Pemasaran: Teori dan Praktik. Bogor: Ghalia

Cheung, C. M. K., Lee, M. K. O., \& Rabjohn, N. (2008). The impact of electronic wordofmouth: the adoption of online opinions in online customer communities. Internet Research, 18(3), 229-247. doi.org/10.1108/10662240810883290. 
Cheung, M. Y., Luo, C., Sia, C. L., \& Chen, H. (2009). Credibility of electronic wordofmouth: informational and normative determinants of on-line consumer recommendations. International Journal of Electronic Commerce, 13(4), 9-38. http:// doi.org/10.2753/JEC1086-4415130402.

Chu, S. C., \& Kim, Y. (2011). Determinants of consumer engagement in electronic wordof-mouth (eWOM) in social networking sites. International Journal of Advertising, 30(1), 47-75. doi.org/10.2501/IJA-30-1-047-075.

De Cannicre, M. H., De Pelsmacker, P., \& Geuens, M. (2009). Relationship quality and the theory of planned behavior models of behavioral intentions and purchase behavior. Journal of Business Research, 62(1), 82-92. http://doi.org/10.1016/j. jbusres.2008.01.001.

Erkan, I. (2016). The influence of electronic word of mouth in social media on consumers' purchase intentions. Doctoral dissertation, London. Brunel University.

Foxall, G. R. (2005). Understanding consumer choice. Basingstoke: Palgrave Macmillan. http://doi.org/10.1057/9780230510029.

Gadermann, A. M., Guhn, M., \& Zumbo, B. D. (2012). Estimating ordinal reliability for Likert-type and ordinal item response data: a conceptual, empirical, and practical guide. Practical Assessment, Research \& Evaluation, 17(3).

Hennig-Thurau, T., Gwinner, K.P., Walsh, G. and Gremler, D.D. (2004), Electronic wordof-mouth via consumer-opinion platforms: what motivates consumers to articulate themselves on the internet?. Journal of Interactive Marketing, Vol. 18 (1), 38-52.

I. Erkan and C. Evans. (2016). The influence of eWOM in social media on consumers' purchase intentions: An extended approach to information adoption," Computers in Human Behavior, vol. 61, 47-55.

Infosino, W. J. (1986). Forecasting new product sales from likelihood of purchase ratings. Marketing Science, 5(4), 372-384. http://doi.org/10.1287/mksc.5.4.372.

J.G. Udo, K.K. Bagchi, and P.J. Kirs. (2010). An assessment of customers' e-service quality perception, satisfaction and intention. International Journal of Information Management, 30(6), 481-492. http://dx.doi.org/10.1016/j.ijinfomgt.2010.03.005.

Korea Pharmaceutical Traders Association. (2012). Korean Pharmaceutical and cosmetics export statistics, //www.kpta.or.kr/eng/Info/statistics_export.asp Accessed $13 / 03 / 2019$ at 22:08pm.

Łopaciuk, A., \& Łoboda, M. (2013). Global beauty industry trends in the 21 st century. In Management, knowledge and learning international conference, 19-21.

M. M. M. A. Riffai, K. Grant, and D. Edgar. (2012). Big TAM in Oman: Exploring the promise of online banking, its adoption by customers and challenges of banking in Oman. International Journal of Information Management, Vol. 32 (3), 239-250.

Morrison, D. G. (1979). Purchase intentions and purchase behavior. Journal of Marketing, 43(2), 65-74. http://doi.org/10.2307/1250742.

P. Chatterjee. (2001). Online review: Do consumers use them. Advances in Consumer Research, 28(1), 129-133, 200.

R. Petty and J. Cacioppo. (1983). Communication and Persuasion: Central and Peripheral Routes to Attitude Change. Springer-Verlag: New York.

Shu, M. L., \& Scott, N. (2014). Influence of social media on chinese students' choice of an overseas study destination: an information adoption model perspective. Journal of Travel \& Tourism Marketing, 31(2), 286-302. http://doi.org/10.1080/ 10548408.2014.873318. 
Special report: Pots of promise - the beauty business. (2003). The Economist, 367, 71. Retrieved from //search.proquest.com/docview/224021454?accountid=45753 $25 / 03 / 2019$ at $11: 24 \mathrm{pm}$.

Sugiyono. (2012). Metode Penelitian Kuantitatif Kualitatif dan R\&D. Bandung: Alfabeta. . (2013). Metodologi Penelitian Kuantitatif, Kualitatif Dan R\&D. Bandung: Alfabeta.

www.innisfree.com/sg/en/BrandPage.do?pageName=brand history accessed 12/03/2019 (9:16am).

Sun, B., \& Morwitz, V. G. (2010). Stated intentions and purchase behavior: a unified model. International Journal of Research in Marketing, 27(4), 356e366. http://doi. org/10.1016/j.ijresmar.2010.06.001.

S. W. Sussman and W. S. Siegel. (2003). Informational influence in organizations: An Integrated approach to knowledge adoption. Information Systems Research, vol. 14(1), 47-65.

Wan, F., Youn, S., and Fang, T. (2001). Passionate Surfers in Image-Driven Consumer Culture: Fashion-Conscious, Appearance-Savvy People and Their Way of Life. Advances in Consumer Research, Vol. 28, 266-274.

Wolny, J., \& Mueller, C. (2013). Analysis of fashion consumers' motives to engage in electronic word-of-mouth communication through social media platforms. Journal of Marketing Management, 29(5-6), 562-583. http://doi.org/10.1080/ $0267257 X .2013 .778324$. 